OPEN ACCESS

Edited by:

Jun Wang

University of Wisconsin-Madison, United States

Reviewed by: Jie Cheng,

Harbin Engineering University, China Guang $\mathrm{Hu}$,

X'an Jiaotong University, China

${ }^{*}$ Correspondence: Lianjie Wang mcd2264@126.com

Specialty section: This article was submitted to

Nuclear Energy,

a section of the journal Frontiers in Energy Research

Received: 26 August 2021 Accepted: 25 October 2021 Published: 25 November 2021

Citation:

Lu D, Wang L, Cai Y, Wang D and Zhang C (2021) Physical Design of

High-Performance Fuel Assembly Based on Fully Ceramic Microencapsulated Fuel for Supercritical $\mathrm{CO}_{2}$ Cooled Reactor.

Front. Energy Res. 9:764905. doi: 10.3389/fenrg.2021.764905

\section{Physical Design of High-Performance Fuel Assembly Based on Fully Ceramic Microencapsulated Fuel for Supercritical $\mathrm{CO}_{2}$ Cooled Reactor}

\author{
Di Lu, Lianjie Wang *, Yun Cai, Dongyong Wang and Ce Zhang \\ Nuclear Power Institute of China (NPIC), Chengdu, China
}

Fully ceramic microencapsulated fuel (FCM) is employed in the supercritical $\mathrm{CO}_{2}\left(\mathrm{~S}-\mathrm{CO}_{2}\right)$ cooled reactor as accident tolerant fuel (ATF). Although the fuel and the assembly substrate contain $\mathrm{SiC}$, the assembly cannot be sufficiently moderated due to the weak moderating performance of $\mathrm{S}-\mathrm{CO}_{2}$, which affects the neutronics economy seriously. In this study, a new fuel assembly based on FCM fuel is proposed for the $\mathrm{S}-\mathrm{CO}_{2}$ cooled reactor. Besides, the solid moderator rod is introduced into the design. Although the introduction of moderator rods can effectively improve the moderation performance of $\mathrm{S}-\mathrm{CO}_{2}$ reactor assembly, it will lead to the deterioration of uniform moderation. To further improve the uniform moderation, arrangement of moderator rods and fuel enrichment partition are studied. Finally, the results show clearly that a better balance between uniform moderation and sufficient moderation can be obtained in the high-performance $\mathrm{S}-\mathrm{CO}_{2}$ reactor assembly.

Keywords: supercritical $\mathrm{CO}_{2}$ cooled reactor, fuel assembly (FA), FCM fuel, sufficient moderation, uniform moderation

\section{INTRODUCTION}

By taking advantage of the appropriate critical pressure, high density, stability, and sluggishness of $\mathrm{CO}_{2}$ near its critical point, the use of supercritical $\mathrm{CO}_{2}\left(\mathrm{~S}-\mathrm{CO}_{2}\right)$ as a coolant in the direct cycle reactor is evaluated ( $\mathrm{Ahn}$ et al., 2015; Wu et al., 2020). The $\mathrm{S}-\mathrm{CO}_{2}$-cooled reactor, as a promising innovative reactor, has the advantages of simple system, high thermal efficiency, small volume, and light weight, and it represents an important development direction for nuclear energy innovation and development (Michael, 2004).

Safety and economics are the main objectives of the $\mathrm{S}-\mathrm{CO}_{2}$-cooled reactor. A new fuel concept is referred to as accident-tolerant fuels (ATFs) are capable of mitigating the potential consequences of beyond-design-basis accidents (Bragg-Sitton, 2014). The fully ceramic microencapsulated (FCM) fuel (Terrani et al., 2012) has become one among the ATF options which is based on tristructural isotropic (TRISO) (Bragg-Sitton and Carmack, 2015)-coated particles embedded in silicon carbide (SiC) matrix. FCM fuel borrows from the TRISO particle design from the high-temperature gas reactor (HTGR) technology but uses $\mathrm{SiC}$ as a matrix material rather than graphite in HTGR. Benefiting from the multiple barriers of TRISO and SiC matrix, FCM fuel has extremely high radioactivity retention capability compared to that of the conventional standard $\mathrm{UO}_{2}$ fuel. By the advantages of safety, a new fuel assembly based on the FCM fuel is proposed for the $\mathrm{S}-\mathrm{CO}_{2}$-cooled reactor in this study. 
A

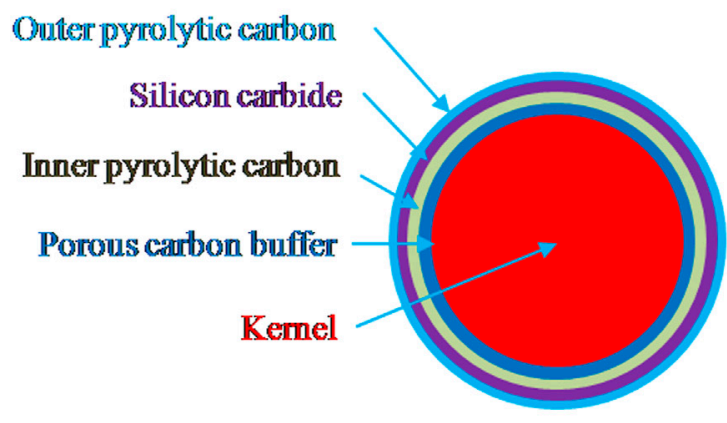

A TRISO particle
B

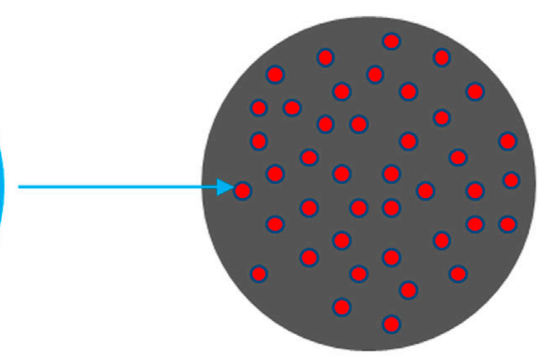

A FCM fuel pin

FIGURE 1 | Design of FCM fuel.

TABLE 1 | TRISO particle geometry and composition.

\begin{tabular}{|c|c|c|}
\hline Layer & Radius (mm) & Density $\left(\mathrm{g} / \mathrm{cm}^{3}\right)$ \\
\hline Kernel & 0.4000 & 10.41 \\
\hline Porous carbon buffer & 0.4500 & 1.100 \\
\hline Inner pyrolytic carbon & 0.4850 & 1.900 \\
\hline Silicon carbide & 0.5200 & 3.180 \\
\hline Outer pyrolytic carbon & 0.5400 & 1.900 \\
\hline
\end{tabular}

TABLE 2 | FCM fuel design parameters.

\begin{tabular}{lcc} 
Parameter & Value & Unit \\
\hline Fuel compact outer radius & 8.3500 & $\mathrm{~mm}$ \\
Gas gap outer radius & 8.4000 & $\mathrm{~mm}$ \\
SiC Clad outer radius & 8.9000 & $\mathrm{~mm}$ \\
${ }^{235}$ U enrichment & $19.75 \%$ & - \\
TRISO particle share & $40 \%$ & -
\end{tabular}

In further research, although the FCM fuel contains moderation materials such as $\mathrm{SiC}$, the assembly cannot be sufficiently moderated due to the weak moderating performance of $\mathrm{S}-\mathrm{CO}_{2}$, which affects the neutronics economy seriously. The study on improving the deficiency of weak moderating performance is described in this article.

Unlike the light water moderated or heavy water moderated (Zhang et al.,2019; Zhang et al.,2020) nuclear reactors, the S$\mathrm{CO}_{2}$ cooled reactor needs specific moderator rods to improve the slow-down of neutrons. The introduction of moderator rods can effectively improve the moderating performance of $\mathrm{S}-\mathrm{CO}_{2}$-cooled reactor, but it will lead to the deterioration of uniform moderation. To further improve the uniform moderation, moderator rod arrangement and fuel enrichment partition method are studied. Finally, this study shows clearly that a better balance between uniform moderation and sufficient moderation can be obtained in the highperformance $\mathrm{S}-\mathrm{CO}_{2}$-cooled reactor assembly.

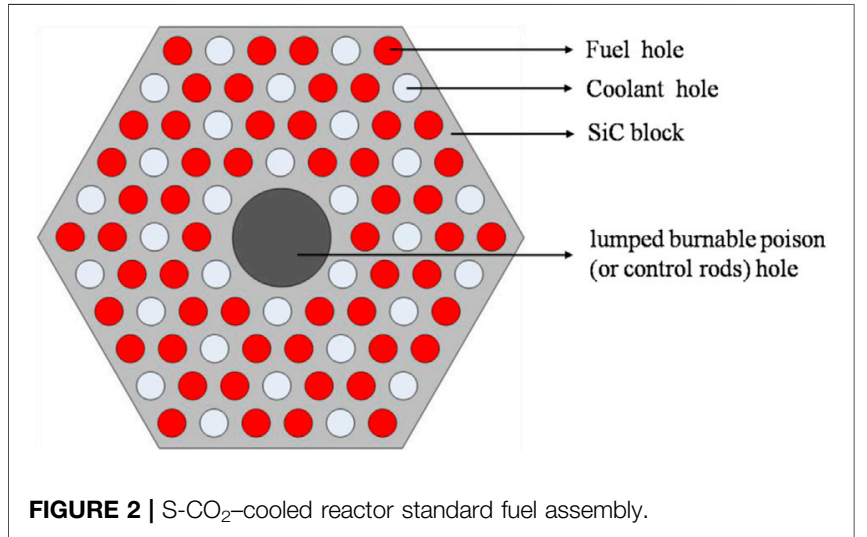

TABLE 3 | FCM fuel design parameters.

Parameter

Value Unit

$\mathrm{SiC}$ block length

$\mathrm{SiC}$ block width

Fuel/Coolant hold diameter

2,500.00 mm

Minimum web thickness

$\mathrm{SiC}$ Clad outer radius

lumped burnable poison (or control rods) hole diameter

Fuel hold number

Coolant hold number

$\cup$ weight per assembly

54

44.48

$\mathrm{kg}$

\section{FULLY CERAMIC MICROENCAPSULATED FUEL ASSEMBLY OF S- $\mathrm{CO}_{2}$-COOLED REACTOR DESIGN}

\section{Standard Fuel Assembly of S- $\mathrm{CO}_{2}-$ Cooled Reactor Design}

An FCM fuel with a TRISO particle is shown in Figure 1. The TRISO particle geometry and composition are given in Table $\mathbf{1}$ and the FCM fuel design parameters are given in Table 2. In this 


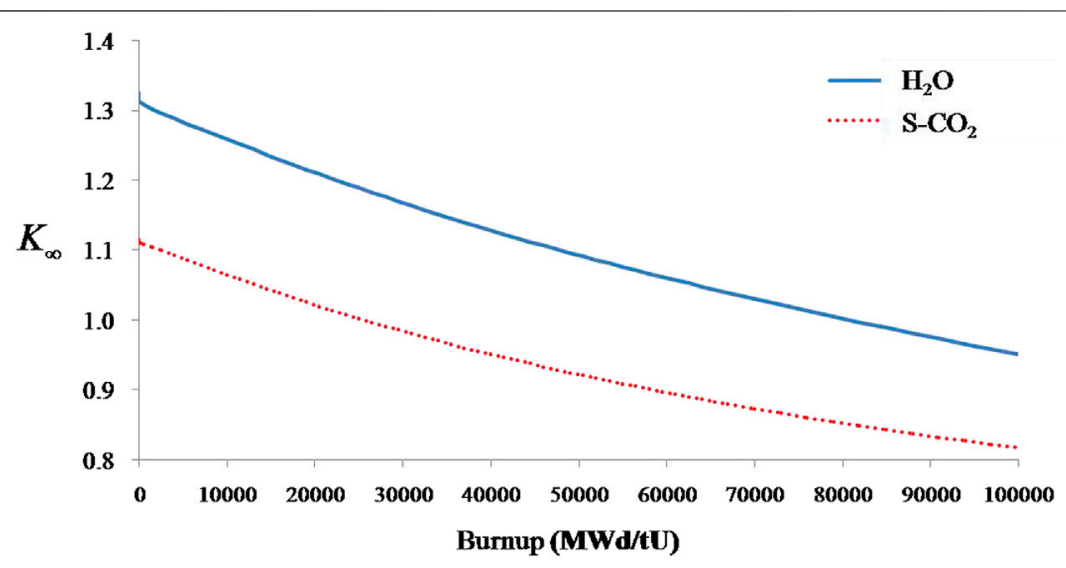

FIGURE $3 \mid K_{\infty}$ versus fuel burn up.

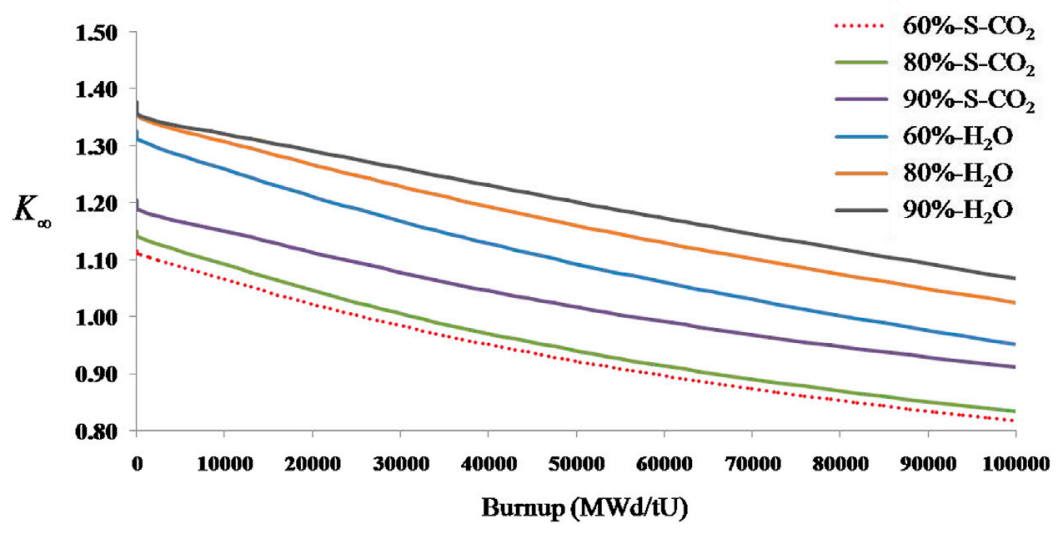

FIGURE $4 \mid K_{\infty}$ by different $\mathrm{SiC}$ matrix share versus burn up.

design, the TRISO particles account for $40 \%$ of the volume in FCM fuel and the enrichment of ${ }^{235} \mathrm{U}$ reaches $19.75 \%$.

The standard fuel assembly of S- $\mathrm{CO}_{2}$-cooled reactor in this study is shown in Figure 2; it contains SiC block, fuel holes, coolant holes, and lumped burnable poison (or control rods) hole. The assembly design parameters are given in Table 3. Each block is a right hexagonal prism with a dimension of $2,500 \mathrm{~mm}$ in length and $240 \mathrm{~mm}$ across the flats of the hexagonal cross section. Fuel and coolant holes run parallel through the length of the block in a regular triangular pattern of nominally two fuel holes per coolant hole. The pitch of the fuel and coolant hole array is $18 \mathrm{~mm}$. The minimum web thickness between the fuel hold and coolant hole is $6 \mathrm{~mm}$ and this web provides an additional barrier

TABLE 4 | YH $\mathrm{YH}_{1.8}$ solid moderator pin geometry and composition.

\section{Layer}

Kernel

Cladding

\section{Radius (mm)}

$$
8.4000
$$

8.9000
Material

$\mathrm{YH}_{1.8}$ stainless steel to the release of metallic fission products. In order to get an effective control of reactivity, a lumped burnable poison (or control rods) hole $(72 \mathrm{~mm})$ is added to the center of standard fuel assembly.

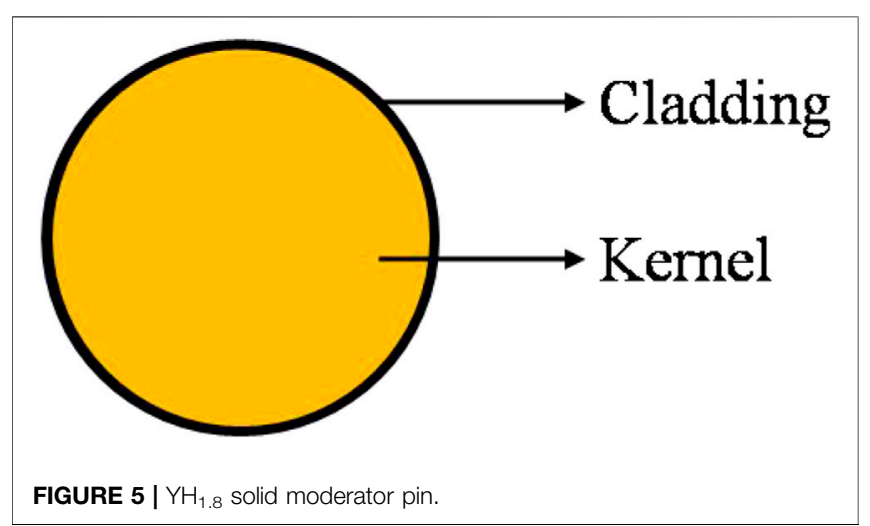




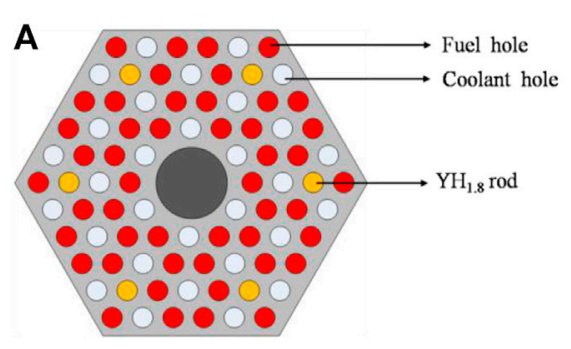

number of $\mathrm{YH}_{1.8}$ rods $=6$

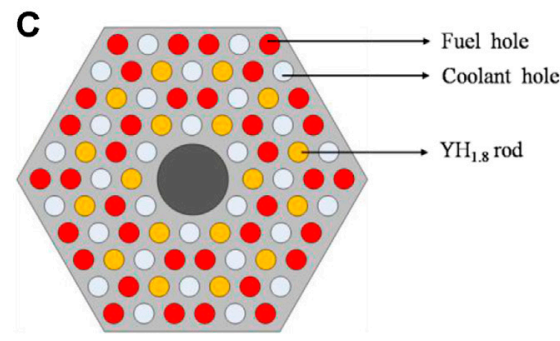

number of $\mathrm{YH}_{1.8}$ rods $=18$

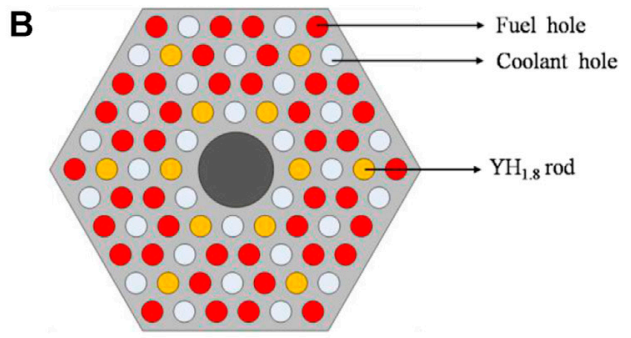

number of $\mathrm{YH}_{1.8}$ rods $=12$

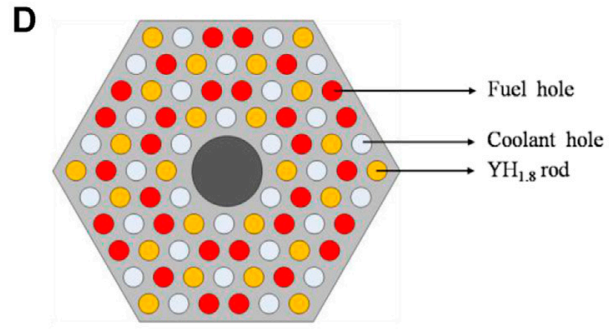

number of $\mathrm{YH}_{1.8}$ rods $=24$

\section{Neutron Moderating Performance Analysis for the Standard Assembly}

To analyze neutron moderating performance for the standard assembly, the light water $\left(\mathrm{H}_{2} \mathrm{O}\right)$ coolant fuel assembly is used for comparison in standard assembly cooling by $\mathrm{S}-\mathrm{CO}_{2}$. Other than replacing coolant with $\mathrm{H}_{2} \mathrm{O}$, the design parameters remain unchanged to compare $\mathrm{S}-\mathrm{CO}_{2}$ assembly and $\mathrm{H}_{2} \mathrm{O}$ assembly in moderating analyses. The calculation in the study is done by using HANDF-E code package developed by the Nuclear Power Institute of China. This code has been used in the analysis of hexagonal assembly because of its high accuracy.

Infinite multiplication factor $\left(K_{\infty}\right)$ is the main parameter that characterizes fuel reactivity. In general, moderating performance largely determines the value of $K_{\infty} . K_{\infty}$ of each assembles as fuel burn up varies, as shown in Figure 3. $K_{\infty}$ of S- $\mathrm{CO}_{2}$ assembly is much less than that of $\mathrm{H}_{2} \mathrm{O}$ under the same fuel burn up. The calculation results clearly show that $\mathrm{S}-\mathrm{CO}_{2}$ assembly has the defect of insufficient moderating performance.

Neutrons can be moderated in the $\mathrm{SiC}$, and increasing the $\mathrm{SiC}$ matrix share of FCM fuel is the most direct way to improve the

\begin{tabular}{cccc}
\hline \multicolumn{2}{c}{ TABLE 5 | $\mathrm{YH}_{1.8}$ solid moderator rods number setting. } \\
\hline $\mathbf{Y H}_{\mathbf{1 . 8}}$ rods number & Fuel rods number & $\begin{array}{c}\text { Relative } \\
\text { share of fuel }\end{array}$ \\
\hline 1 & 0 & 54 & 1.000 \\
2 & 6 & 48 & 0.889 \\
3 & 12 & 42 & 0.778 \\
4 & 18 & 36 & 0.667 \\
5 & 24 & 30 & 0.556
\end{tabular}

moderating performance. The $\mathrm{SiC}$ matrix share increases from 60 to $80 \%$, or even $90 \%$, and then $K_{\infty}$ by different $\mathrm{SiC}$ matrix share as fuel burn up varies is shown in Figure 4. The calculation results clearly show that increasing $\mathrm{SiC}$ matrix share is beneficial to enhance moderating performance and improve fuel reactivity. Figure 4 also presents $K_{\infty}$ of $\mathrm{H}_{2} \mathrm{O}$ assembly by different $\mathrm{SiC}$ matrix share as fuel burn up varies. Even if the matrix share changes, $K_{\infty}$ of $\mathrm{H}_{2} \mathrm{O}$ is still much greater than that of $\mathrm{S}-\mathrm{CO}_{2}$. These results show that the method of increasing the $\mathrm{SiC}$ matrix share has a limited effect on improving the moderating performance.

In fact, in terms of fuel burn up and core volume, increasing $\mathrm{SiC}$ matrix share is not a good idea; it means the TRISO particle share is reduced and fuel burn up will be grow greatly. To reduce fuel burn up, a larger number of assembles will be used in core, resulting in a larger core volume, and the large core volume makes the design of pressure vessels under high temperature and pressure a great challenge. Therefore, the method to improve the moderating performance should minimize the increase in core volume.

\section{NEUTRONICS ANALYSIS FOR THE DESIGN OF $\mathrm{YH}_{1.8}$ IN THE STANDARD ASSEMBLY}

Because of stronger neutron moderating capacity, metal hydride has been used as a solid moderator in reactors. Yttrium hydride $\left(\mathrm{YH}_{1.8}\right)$ is more suitable to use in the $\mathrm{S}-\mathrm{CO}_{2}$ cooled reactor because it is more stable than zirconium hydride $\left(\mathrm{ZrH}_{1.6}\right)$ at high temperature.

The design of $\mathrm{YH}_{1.8}$ solid moderator rod used in this study is shown in Figure 5. To reduce the release of hydrogen atoms, 


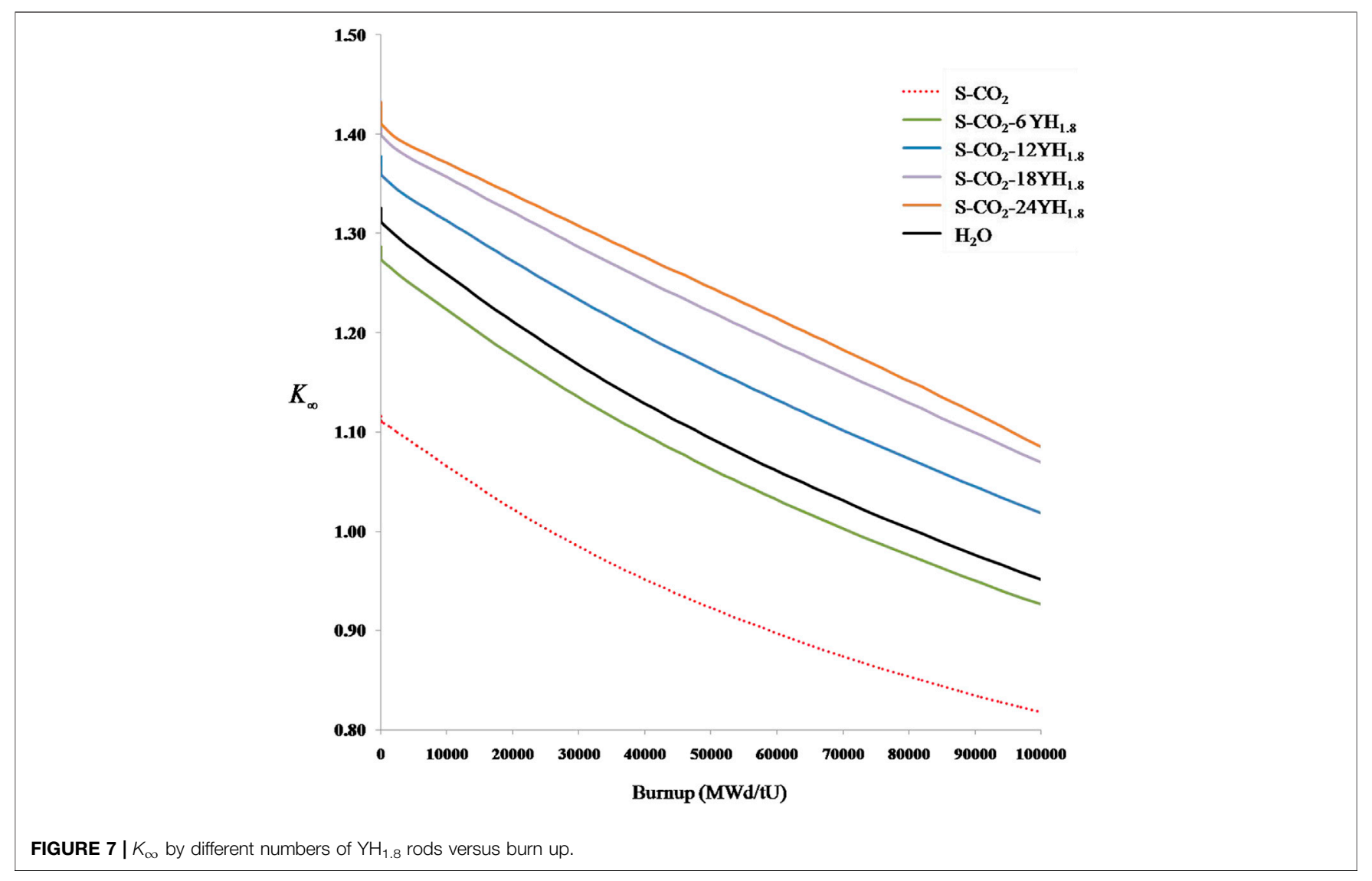

the solid moderator rod is coated with stainless steel. The $\mathrm{YH}_{1.8}$ solid moderator rod geometry and composition are given in Table 4.

The moderating method is to insert the $\mathrm{YH}_{1.8}$ solid moderator rod into part of fuel holds instead of the FCM fuel. The moderating performance of assembly can be changed by using different number of $\mathrm{YH}_{1.8}$ solid moderator rods. The number of $\mathrm{YH}_{1.8}$ solid moderator rod analyzed in this study is shown in Table 5, and the arrangements of the $\mathrm{YH}_{1.8}$ solid moderator rods are shown in Figure 6.
$K_{\infty}$ by different $\mathrm{YH}_{1.8}$ solid moderator rod number as fuel burn up varies is shown in Figure 7. The calculation results clearly show that adding $\mathrm{YH}_{1.8}$ solid moderator rod can significantly enhance moderating performance and then improve the fuel reactivity greatly. $K_{\infty}$ of $\mathrm{H}_{2} \mathrm{O}$ is also described in Figure 6. When the number of $\mathrm{YH}_{1.8}$ solid moderator rods is greater than 12 , the $K_{\infty}$ of $\mathrm{S}-\mathrm{CO}_{2}$ assembly is significantly larger than that of $\mathrm{H}_{2} \mathrm{O}$ assembly. These results show that moderating performance can be improved significantly by inserting the $\mathrm{YH}_{1.8}$ solid moderator rod. When $12 \mathrm{YH}_{1.8}$ solid

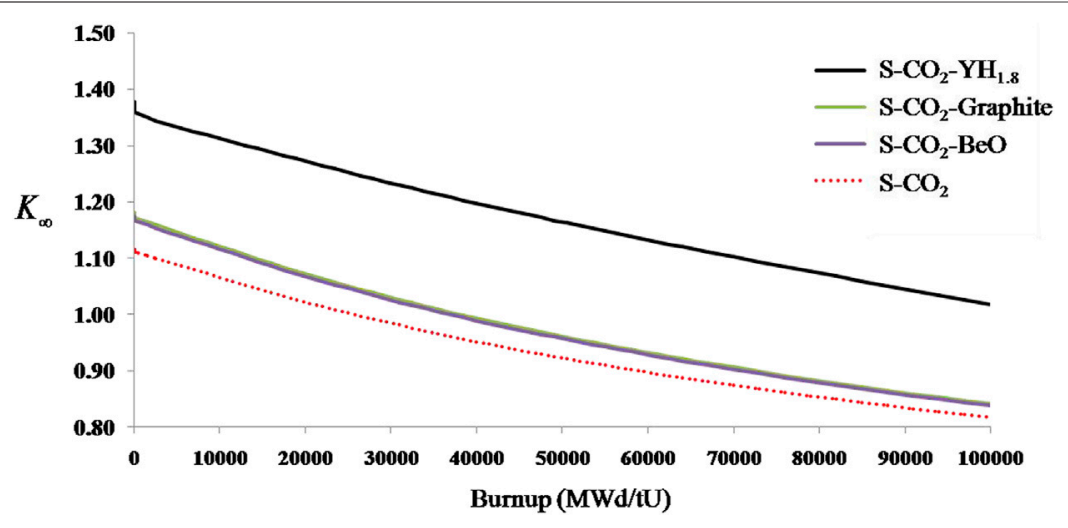

FIGURE $8 \mid K_{\infty}$ by different moderating materials versus burn up. 

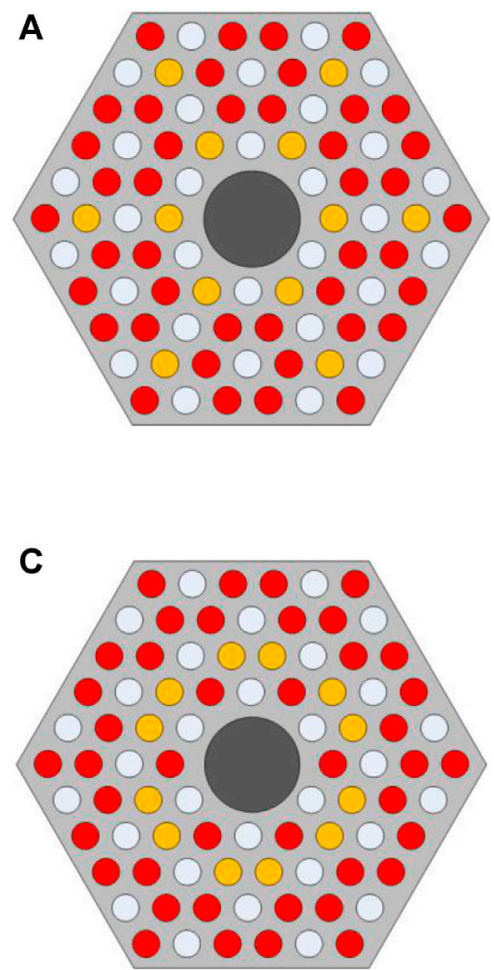
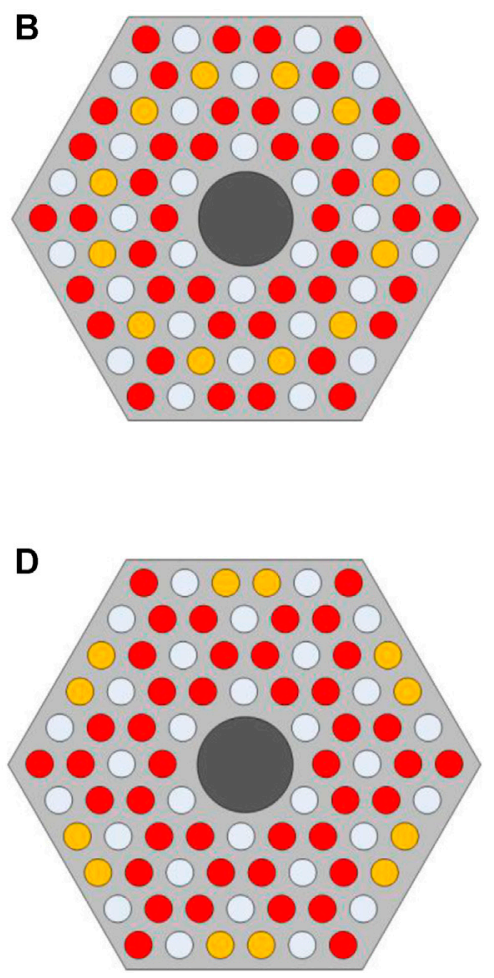

FIGURE 9 | Arrangements of $12 \mathrm{YH}_{1.8}$ solid moderator rods.

moderator rods were inserted, the $\mathrm{S}-\mathrm{CO}_{2}$ assembly was moderated sufficiently and the fuel share was reduced by only $22.2 \%$.

The moderating effect of different materials was further studied. Commonly used moderating materials such as graphite and $\mathrm{BeO}$ are used for comparison with $\mathrm{YH}_{1.8} . K_{\infty}$ of different moderating materials as fuel burn up varies are shown in Figure 8. $K_{\infty}$ of $\mathrm{YH}_{1.8}$ is significantly larger than that of graphite and $\mathrm{BeO}$. The results show that using $\mathrm{YH}_{1.8}$ as a moderator is the best choice to improve the moderating performance of $\mathrm{S}-\mathrm{CO}_{2}$ assembly.

\section{UNIFORM MODERATING DESIGN FOR THE S- $\mathrm{CO}_{2}$ ASSEMBLY}

Inserting the $\mathrm{YH}_{1.8}$ solid moderator rods cause uneven moderating in the assembly. In order to get uniform moderating, the arrangement of the moderators must be studied.

The moderating effect and the change of fuel share were considered, and then the number of $\mathrm{YH}_{1.8}$ solid moderator rods is selected as 12 in this section. The different arrangements of $\mathrm{YH}_{1.8}$ solid moderator rods are shown in Figure 9 and power uneven factor by different solid

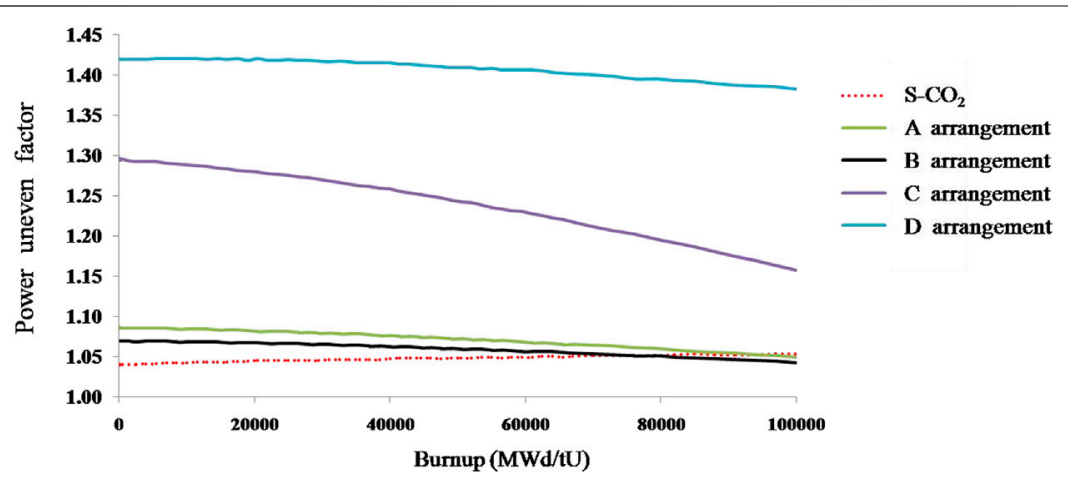

FIGURE 10 | Power uneven factor by different solid moderator arrangements. 


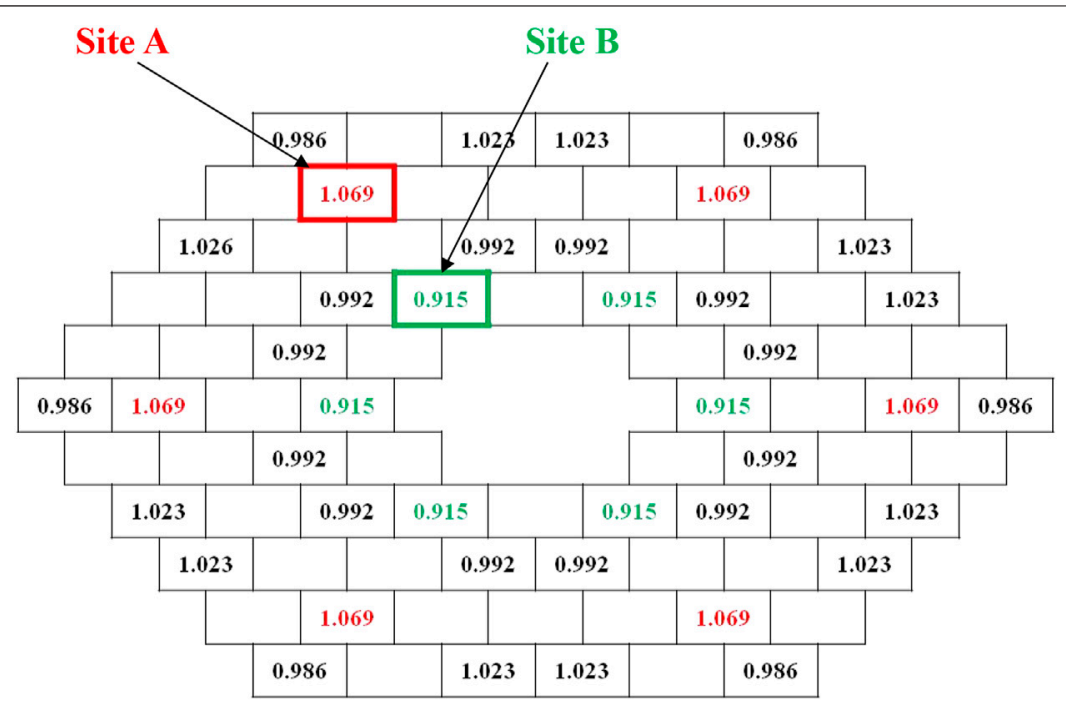

FIGURE 11 | Relative power distribution of $\mathrm{S}-\mathrm{CO}_{2}$ assembly using arrangement B (BOL).

moderator arrangements as fuel burn up varies are shown in Figure 10. The arrangement $\mathrm{B}$ of solid moderator obtains the lowest uneven factor and becomes the preferred arrangement in this study.

Figure 11 presents the BOL (Begin Of Life) relative power distribution of $\mathrm{S}-\mathrm{CO}_{2}$ assembly using arrangement $\mathrm{B}$. Figure 11 clearly shows that the maximum power is at site $\mathrm{A}$ and the minimum power is at site B. In order to further realize the uniform moderating to reduce the power uneven factor, the fuel share of FCM partitioning method is applied in the $\mathrm{S}-\mathrm{CO}_{2}$ assembly design. The fuel share of FCM is reduced from 40 to $35 \%$ at site $\mathrm{A}$ which have maximum power and the fuel share of
FCM is increased from 40 to $45 \%$ at site B which have minimum power. In addition, this partitioning method ensures that the fuel weight remains the same in the $\mathrm{S}-\mathrm{CO}_{2}$ assembly. The BOL relative power distribution of $\mathrm{S}-\mathrm{CO}_{2}$ assembly using the partitioning method is shown in Figure 12. The relative power at site A decreases from 1.069 to 0.964 , the relative power at site B increases from 0.915 to 1.005 , and then the uneven factor decreases from 1.069 to 1.028 . Figure 13 presents a power uneven factor by arrangement $\mathrm{B}$ with the partitioning method as fuel burn up varies; it shows that the fuel share of the FCM partitioning method can achieve more uniform moderating and power distribution.

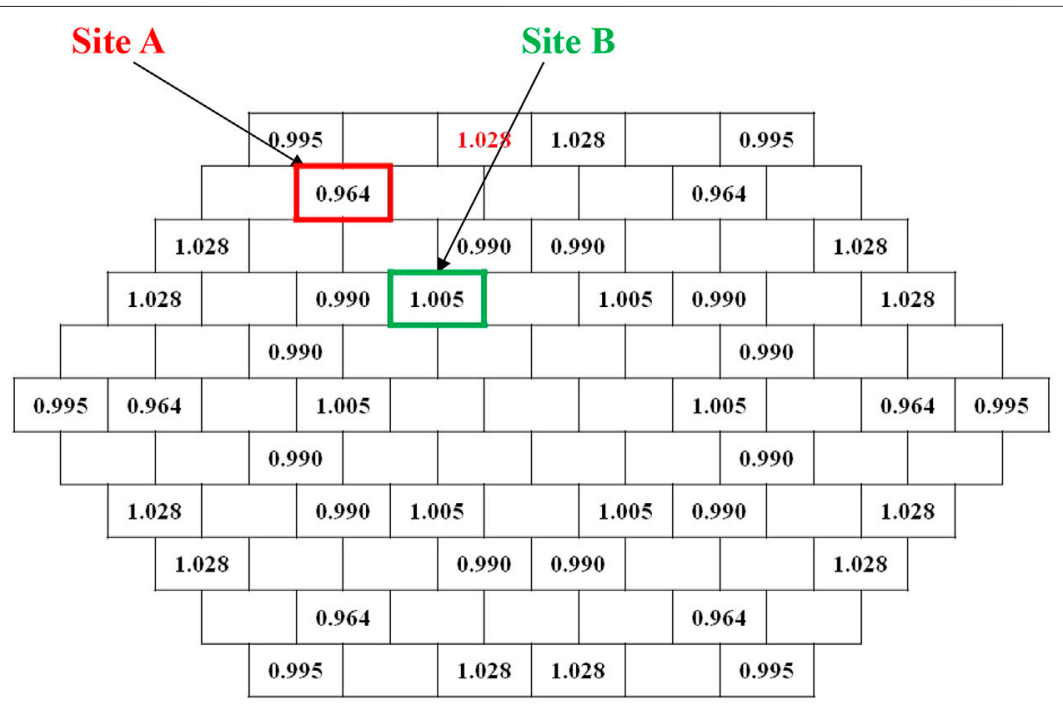

FIGURE 12 | Relative power distribution of $\mathrm{S}-\mathrm{CO}_{2}$ assembly using the partitioning method (BOL). 


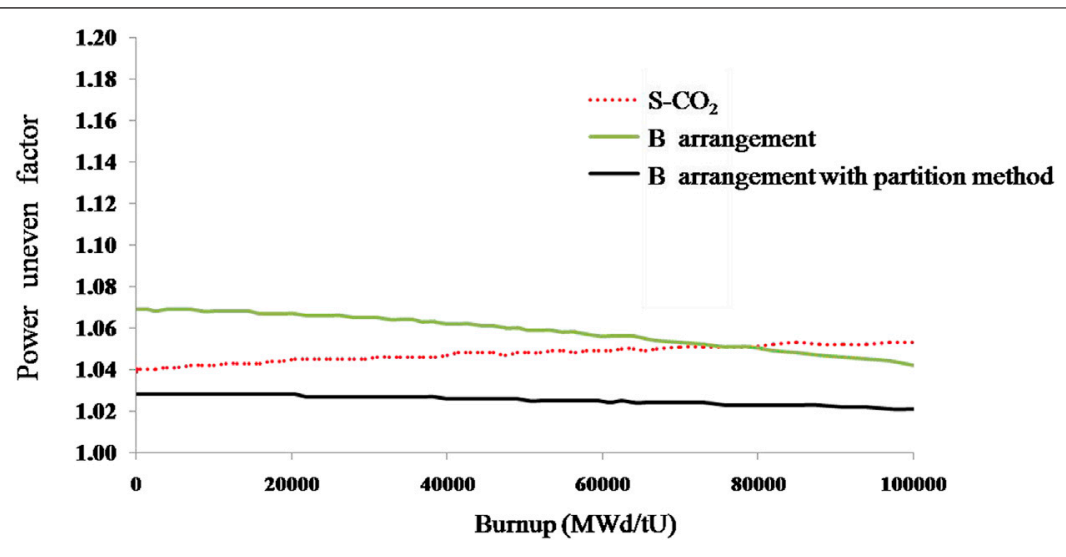

FIGURE 13 | Power uneven factor by arrangement B with the partitioning method.

\section{CONCLUSION}

As a new type reactor with development potential, the $\mathrm{S}-\mathrm{CO}_{2}$-cooled reactor has many advantages, such as simple system, high thermal efficiency, and small volume. FCM fuel which is a potential option of ATF is capable to mitigate the potential consequences of beyond-design-basis accidents and become the preferred type of fuel for the $\mathrm{S}-\mathrm{CO}_{2}$-cooled reactor.

In this article, a new fuel assembly design concept based on FCM fuel for $\mathrm{S}-\mathrm{CO}_{2}$-cooled reactor is proposed. Then, the design of $\mathrm{YH}_{1.8}$ solid moderator rod was adopted to improve the moderating performance of the fuel assembly. In order to deal with the moderating non-uniformity caused by the moderator, the arrangement of moderators and the method of fuel share partitioning were well studied, and then the high-performance fuel assembly based on FCM fuel for $\mathrm{S}-\mathrm{CO}_{2}-$ cooled reactor is proposed at last. The main conclusions of the study are as follows:

1) The fuel assembly based on the FCM fuel for the $\mathrm{S}-\mathrm{CO}_{2}$-cooled reactor was proposed because of the safety advantage. Due to the weak moderating performance of $\mathrm{S}-\mathrm{CO}_{2}$, the neutrons in this assembly cannot be sufficiently moderated and affects the neutronics economy seriously.

2) As it is superior to the method of adjusting the $\mathrm{SiC}$ matrix share, the design of $\mathrm{YH}_{1.8}$ solid moderator rod is studied. With this design, the assembly can be sufficiently moderated.

\section{REFERENCES}

Ahn, Y., Bae, S. J., Kim, M., Cho, S. K., Baik, S., Lee, J. I., et al. (2015). Review of Supercritical CO2 Power Cycle Technology and Current Status of Research and Development. Nucl. Eng. Technology. 47 (6), 647-661. doi:10.1016/ j.net.2015.06.009

Bragg-Sitton, S., and Carmack, W. J. (2015). Update on the DOE's ATF Development Program. Nucl. News. 58, 34-35.

Bragg-Sitton, S. (2014). Development of Advanced Accident Tolerant Fuels for Commercial LWRs. Nucl. News. 57, 83-91.
3) The arrangement of $\mathrm{YH}_{1.8}$ solid moderator rods is proposed, which can effectively improve the uniformity of moderating. The method of fuel share partitioning is studied at last and the fuel assembly is further uniformly moderated.

4) The high-performance fuel assembly based on the FCM fuel which has good safety and economics is suitable for $\mathrm{S}-\mathrm{CO}_{2}$-cooled reactor.

\section{DATA AVAILABILITY STATEMENT}

The raw data supporting the conclusions of this article will be made available by the authors, without undue reservation.

\section{AUTHOR CONTRIBUTIONS}

DL contributed to conceptualization, methodology, and design. LW contributed to conceptualization and methodology. YC performed the calcualtion and analysis. DW funding acquisition and supervision. $\mathrm{CZ}$ visualization and investigation.

\section{FUNDING}

This work is supported by the National Natural Science Foundation of China (Approved no.: 12,075,228).

Michael, A. P. (2004). Reactor Physics Design of Supercritical $\mathrm{CO}_{2}$-Cooled Fast Reactor [D]. Cambridge, MA: Master Thesis of Massachusetts Institute of Technology.

Terrani, K. A., Kiggans, J. O., Katoh, Y., Shimoda, K., Montgomery, F. C., Armstrong, B. L., et al. (2012). Fabrication and Characterization of Fully Ceramic Microencapsulated Fuels. J. Nucl. Mater. 426, 268-276. doi:10.1016/j.jnucmat.2012.03.049

Wu, P., Ma, Y., Gao, C., Liu, W., Shan, J., Huang, Y., et al. (2020). A Review of Research and Development of Supercritical Carbon Dioxide Brayton Cycle Technology in Nuclear Engineering Applications. Nucl. Eng. Des. 368, 110767. doi:10.1016/j.nucengdes.2020.110767

Zhang, T., Xiong, J., Liu, X., Chai, X., Li, W., and Cheng, X. (2019). Conceptual Design of an Innovative Reduced Moderation Thorium-fueled Small Modular 
Reactor with Heavy-water Coolant. Int. J. Energy Res. 43, 8286-8298. doi:10.1002/er.4827

Zhang, T., Liu, X., Xiong, J., and Cheng, X. (2020). Comparisons of Reduced Moderation Small Modular Reactors with Heavy water Coolant. Front. Energy Res. 8, 27.

Conflict of Interest: The authors declare that the research was conducted in the absence of any commercial or financial relationships that could be construed as a potential conflict of interest.

Publisher's Note: All claims expressed in this article are solely those of the authors and do not necessarily represent those of their affiliated organizations, or those of the publisher, the editors, and the reviewers. Any product that may be evaluated in this article, or claim that may be made by its manufacturer, is not guaranteed or endorsed by the publisher.

Copyright $\odot 2021 \mathrm{Lu}$, Wang, Cai, Wang and Zhang. This is an open-access article distributed under the terms of the Creative Commons Attribution License (CC $B Y)$. The use, distribution or reproduction in other forums is permitted, provided the original author(s) and the copyright owner(s) are credited and that the original publication in this journal is cited, in accordance with accepted academic practice. No use, distribution or reproduction is permitted which does not comply with these terms. 